\title{
SEDIMENT EXCHANGE BETWEEN THE SUB-AQUEOUS AND SUB-AERIAL COASTAL
} ZONES.

\author{
Sierd de Vries ${ }^{1}$, Matthieu de Schipper ${ }^{1}$, Marcel Stive ${ }^{1}$ and Roshanka Ranasinghe ${ }^{1,2}$
}

\begin{abstract}
The coastal system consists of a sub-aqueous and a sub-aerial zone which can be separated by a border. At this border sediment exchange takes place from one zone to the other. This paper hypothesizes that conditions and therefore sediment exchange at this border are dependent on active profile characteristics. To analyze morphological developments due to combined marine and aeolian processes data acquired at a measurement site located along the southwest Holland coast is exploited. Based on the monthly morphological profile measurements the border between the marine and aeolian zone is determined. It is found that during accretive conditions the vertical location of this border, and with that the conditions near the border, is dependent not on the foreshore slope of the surf/swash zone as expected but on the slope of the entire active profile.
\end{abstract}

Keywords: Aeolian transport, Morphological measurements, active profile, coastline change

\section{INTRODUCTION}

Over the last few decades, beach/shoreface nourishments have been used as a primary method to maintain the coastline position in the Netherlands. Recent analysis, based on data covering decadal timescales, suggest that shoreface nourishments stimulate dune growth and therefore enhance coastline stability (Van Koningsveld and Lescinski, 2007). However, knowledge on how dune evolution is governed by shoreface parameters is limited. Especially knowledge on how artificial changes in the beach and the shoreface can influence dune evolution is of much practical interest for coastline management. One of the key unknowns is which processes account for sediment exchange between wet and dry coastal zones and how they are influenced. With the aim of expanding the predictive capabilities of coastal evolution this paper focuses on this key challenge in an effort to initiate the development of tools that could predict sediment exchange between the marine and aeolian zone.

Our first step is to define a conceptual approach analyzing coastal evolution of sub-aqueous and sub-aerial zones separately using morphological data. In this paper two datasets of morphological profiles along the Dutch coast are used. 1). The Jarkus dataset consisting of yearly profile measurements since 1960's. This dataset has the advantage of covering the decadal scale (Wijnberg and Terwindt, 1995) but lacks information on the event timescale. 2). To gain more insight into sediment exchange between wet and dry coastal zones on the event timescale a 5 year measurement campaign has been designed and implemented at Vlugtenburg beach in The Netherlands.

This paper describes the measurement site, and presents an initial description of characteristics governing sediment exchange between wet and dry coastal zones.

\section{CONCEPT}

Considering an arbitrary cross shore profile along the Dutch coast a marine zone and an aeolian zone can be distinguished (Figure 1$)$. The border between the two zones $\left(B_{m a}\right)$ can pragmatically be chosen to be located at the Mean Water Level (MWL). Assuming that sediment exchange between the wet and dry coastal zones occurs when sediment crosses the border, both zones act as sinks and sources to one and other. Moreover, the border itself can migrate landward or seaward, potentially resulting in significant sediment exchange between zones.

In fact, to define a transition zone would be more appropriate as physically the waterline is a variable over time (varying for instance with tide). However, we choose at his stage to use a border distinguishing only two zones where the "transitional zone" is parameterized by the border having no spatial dimension in the cross shore. If needed in a later stage, the spatial dimension may be added to the border parameter leading to a transition zone in the end.

A 40 year time series of yearly data of the location of the MWL (taken as a proxy for $B_{m a}$ ) along an accreting part of the Dutch coast shows steady (almost linear) seaward migration (Figure 2). This may suggest that during these 40 years sediment exchange has been fairly constant on a yearly basis. This suggestion is reinforced by profile measurements during the same time and location profile shape has

\footnotetext{
${ }^{1}$ Section of Hydraulic engineering, Delft University of Technology, Stevinweg 1, Delft, $2628 \mathrm{CN}$, The Netherlands

${ }^{2}$ Department of Water Engineering, UNESCO-IHE, PO Box 3015, 2601 DA Delft, The Netherlands
} 


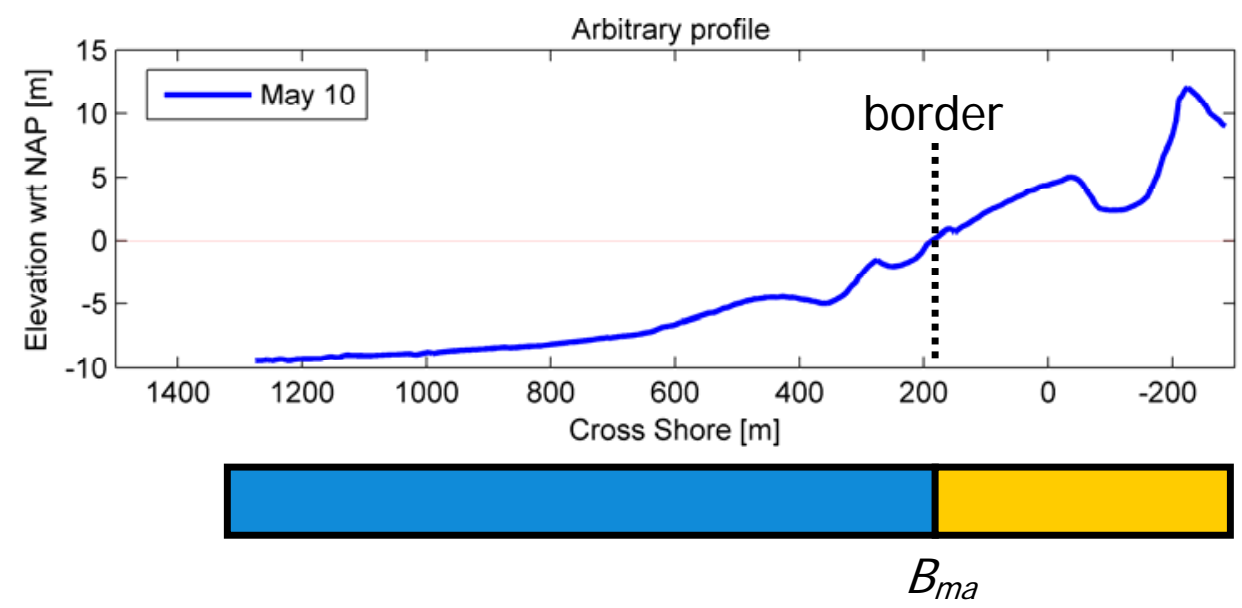

Figure 1. Concept of separating aeolian zone from marine zone and defining a boundary $B_{m a}$ between the marine zone (blue) and aeolian zone (yellow).

remained fairly constant during these 40 years while the sub-aqueous and sub-aerial profile show a seaward shift of a similar distance.

Traditionally coastal studies focus on processes seaward of the $B_{m a}$. Hydrodynamic processes alone account for most of the morphological changes in particular when (storm) events are considered. As a consequence, most process based coastal models consider morphological changes due to hydrodynamic forcing only (Delft3D, XBeach, MIKE21). When trying to aggregate process based coastal models to longer timescales the need to include exchange processes at the $B_{m a}$ together with aeolian processes seaward of the $B_{m a}$ arise especially to account for accretion or recovery between erosion events. Several process based models that are combined with empirical data fitting approaches show practical capabilities of coupling marine and aeolian zones (see a recent example by. Hanson et al., 2010). However, these hybrid approaches lack an accurate and validated description of sedimentary processes which is most notable in the aeolian zone and the area around the border between zones.

Processes in the vicinity of the border between marine and aeolian zone are of much interest as this is the only location where sediment exchange can actually take place. At the border between marine and aeolian zone (generally taken as the waterline when considering short timescales), processes governing morphological changes consist of waves, tides and wind. Assuming the hydrodynamic conditions at the waterline to be dependent on foreshore parameters due to the transformation of waves when propagating towards the waterline it is hypothesized that: conditions at the border between aeolian and marine zone are dependent on foreshore parameters. Following this hypothesis sediment exchange between wet and dry coastal zones would likely be dependent on foreshore parameters as well.

In the next section we try to illustrate the border between marine and aeolian zone on the event timescale using morphological profiles gathered at a new measurement site along the Dutch coast, Vlugtenburg beach.
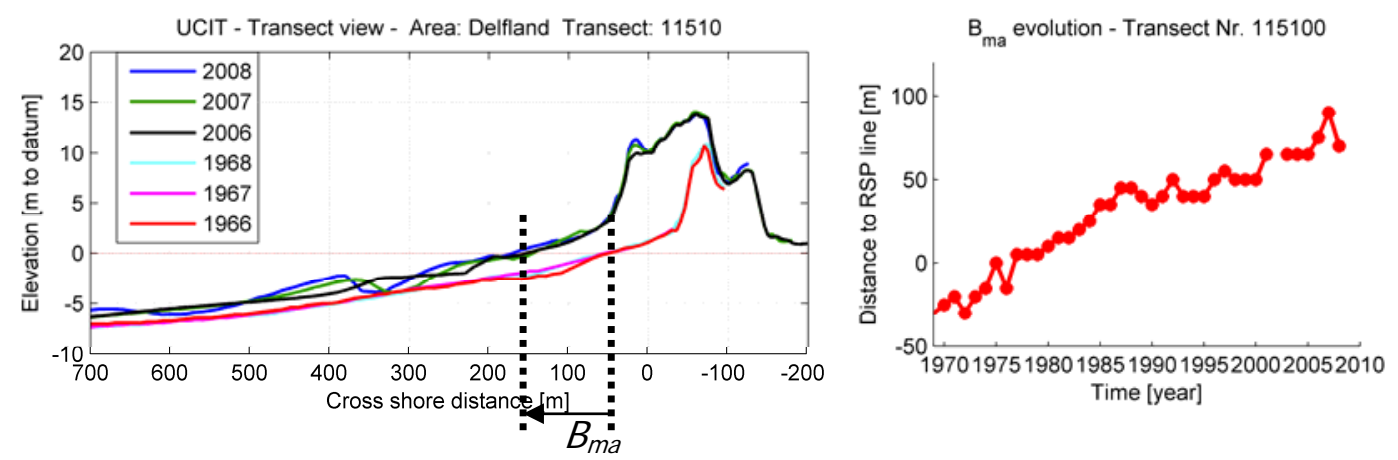

Figure 2. Left panel shows profile development over 40 years; Right panel shows evolution of the $B_{m a}$ over 40 yrs. 

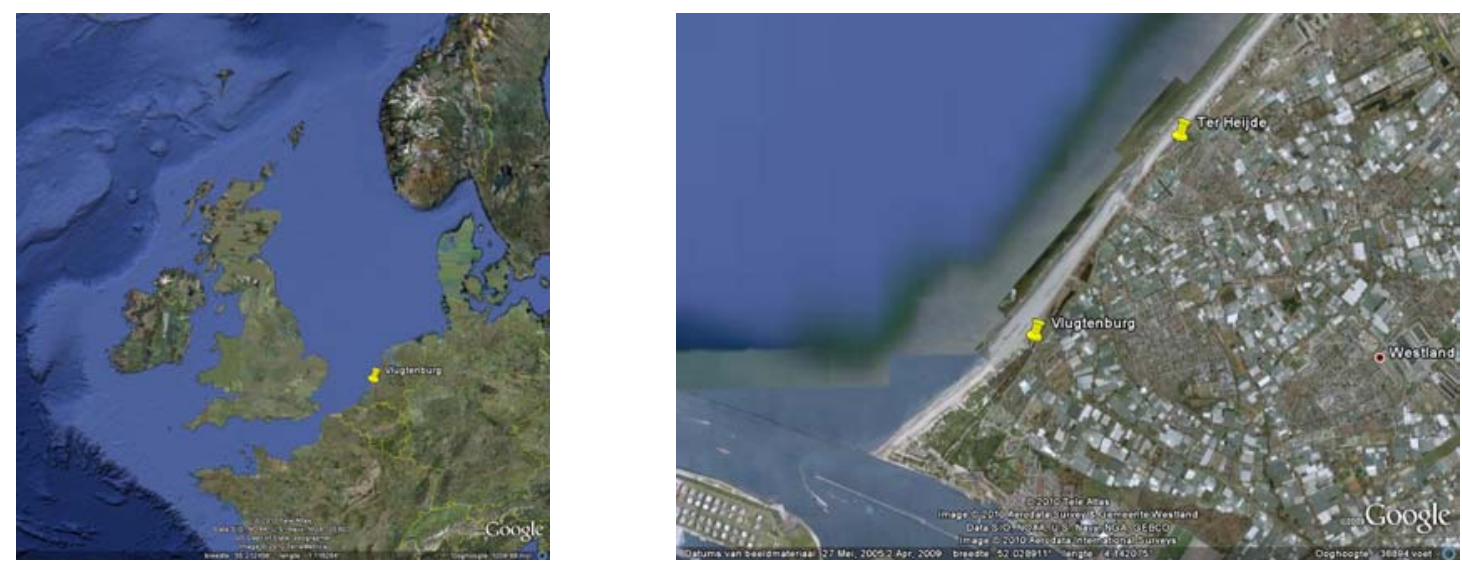

Figure 3. Vlugtenburg beach location

\section{FIELD SITE - VLUGTENBURG BEACH (NL)}

Vlugtenburg beach is located at the southwest of the Holland coast about $2 \mathrm{~km}$ northwards of the 'Noorderdam' bordering the entrance channel to the Port of Rotterdam (Figure 3). This site has been selected to host a project to stimulate nature development to compensate for the loss of natural values during construction and usage of a major harbor extension (Maasvlakte II). The aim of the nature compensation program is to develop a habitat for rare species in the form of a wet dune valley. To stimulate the development of this dune valley a morphological boundary condition, which functions as an initial condition for morphology and nature to develop, is constructed. The morphological situation has been changed significantly compared to the old situation by both foreshore and beach nourishments (Figure 4). The waterline has been moved about $300 \mathrm{~m}$ in seaward direction and a new foredune together with a dune valley in between new and old foredune have been constructed. Figure 5 shows the old and new cross shore profile. Nourishment volume in the shown profile is around 1800 $\mathrm{m}^{3} / \mathrm{m}$. Mean grain size of the nourished sand is relatively fine at around $210 \mu \mathrm{m}$.

Nourishments were completed on the $1^{\text {st }}$ of July 2009 resulting in a complete artificial initial condition for morphology and ecology to develop. It is intended that due to aeolian processes the new constructed foredune will increase in height and size and develop itself towards a mature dune. The dune valley is intended to decrease in height by aeolian sand drift until meeting the groundwater table allowing for a moist/wet habitat for specific flora and fauna to develop.

Generally, mean wave heights and periods along the Dutch coast are $1.2 \mathrm{~m}$ and $5 \mathrm{~s}$ respectively where alongshore differences in wave climate are small (Wijnberg and Terwindt, 1995). The tide is semidiurnal with a neap spring cycle of 1.2 and $2.2 \mathrm{~m}$, respectively. Beach slopes in the surfzone are roughly between 1:40 and 1:50. Therefore the beach at this site can generally be categorized as a dissipative beach with Iribarren parameters (Battjes, 1974) rarely exceeding 0.3.

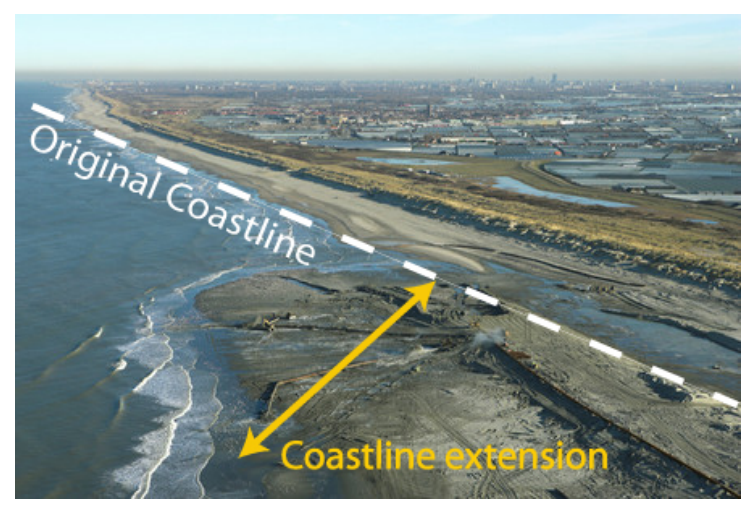

Figure 4. Aerial picture of dredging works showing the significant coastline extension. 


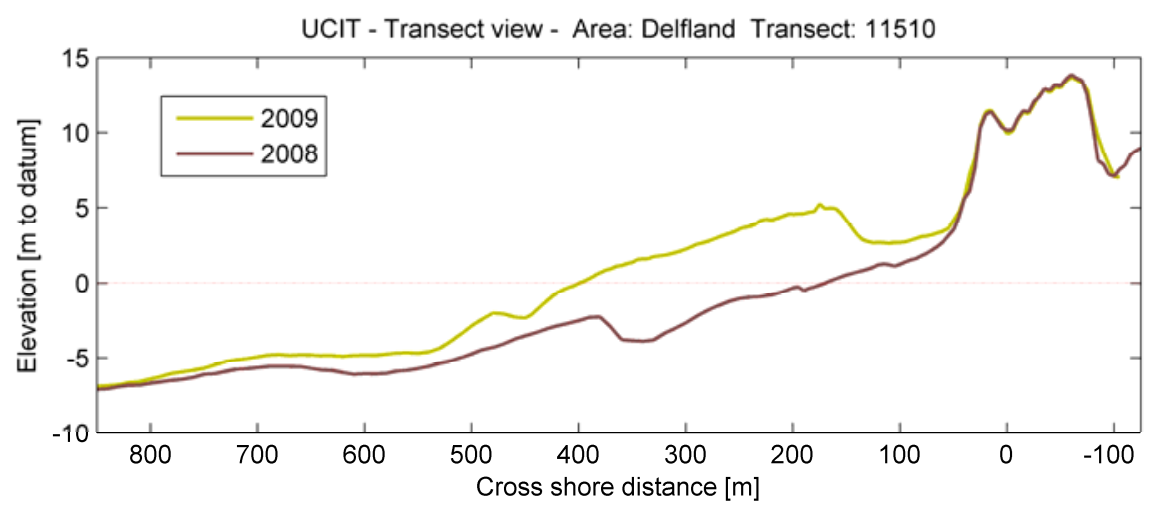

Figure 5. Typical profile at Vlugtenburg beach before and after nourishment.

\section{MEASUREMENTS}

The Delft University of Technology designed and implemented a field program to acquire high resolution (both in space and time) morphological measurements at Vlugtenburg together with process measurements regarding aeolian transport and surf zone hydrodynamics. The morphological measurements consist of monthly topographical measurements of 22 cross shore profiles encompassing both the marine and aeolian zone. Profile spacing is 70-80 m resulting in a domain that covers $1.8 \mathrm{~km}$ alongshore. The marine part of the profile is measured using the TUDelft jetski (van Son et al. 2009) and the aeolian part is measured using conventional RTK GPS techniques. Around storm events survey frequency is increased to focus explicitly on storm impact and its consecutive recovery.

To particularly focus on aeolian development 2D cross shore arrays of sediment samples and cone penetration tests (CPT's) were collected in addition to the morphological measurements. Moreover an airborne LIDAR survey was conducted in August, 2009 for a high resolution morphological representation of the dune area to allow for future studies of dune development and the role of vegetation in particular. Environmental forcing conditions are continuously acquired from a nearby weather station and directional wave buoy. In this paper, only the monthly morphological measurements are considered.

At time of writing the first full year of measurements are available. The mean topography of the measurement domain is shown in Figure 6. Unfortunately no significant high energetic events occurred during this time and thus measured changes are rather modest.

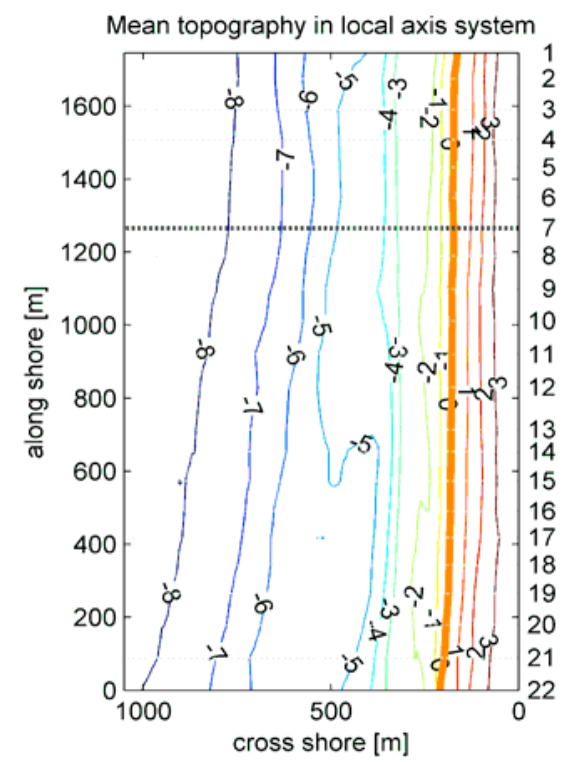

Figure 6. Mean topography of the measurement area. Profile nr 7 used for data analysis indicated by dotted line 


\section{DATA ANALYSIS}

Figure 7 (top panel) shows all consecutive profile measurements of profile $\mathrm{nr} 7$. As can be seen from the variations in monthly measured topography, the marine zone is more variable than the aeolian zone along the profile. Figure 7 (bottom panel) shows the measured variance along profile $\mathrm{nr} 7$. As expected, minimal variability is seen seaward of the depth of closure (around $-8 \mathrm{~m} \mathrm{NAP}$ ). The variability increases rapidly in the foreshore zone and then decreases sharply on the landward side of the profile around +2 m NAP. This +2 m NAP is coherent with the expected maximum water level based on tides and wave runup. We assume that this position represents the aforementioned border between marine and aeolian zone $\left(B_{m a}\right)$. Landwards of the $B_{m a}$ no marine processes are present and seawards of the $B_{m a}$ morphological changes are mainly governed by marine processes.

$B_{m a}$ locations for all of the 22 measured profiles show alongshore differences in the elevation (above NAP) of the $B_{m a}$. Figure 8a shows that there is a clear alongshore gradient in the elevation of the $B_{m a}$ ranging from 1.8 - $2.7 \mathrm{~m}$ NAP over an alongshore distance of $1800 \mathrm{~m}$.

Assuming that the elevation of the $B_{m a}$ is influenced by hydrodynamic conditions and assuming that there are no variations in wave conditions offshore, foreshore slopes might be of influence. Several authors have found runup characteristics including vertical runup levels to be dependent on local foreshore slopes (Ruggiero et al., 2004, Ruessink et al., 1998). In these cases the very nearshore slope of the zone where wave transformation and runup takes place was considered. In line with these studies we consider the foreshore slope where wave transformation takes place along the 22 survey profiles taking the best linear fit between the $B_{m a}$ and the -4 m NAP (Figures $8 \mathrm{~b}$ and c). Foreshore slopes along the 22 profiles vary between $0.021-0.023(1: 47-1: 43)$. This alongshore variation is limited and the expected correlation with the elevation of the $B_{m a}$ is not observed (Figure 9 ).

Alternatively, we suggest considering the slope of the entire active profile taking the closure depth (-8 m NAP) as the seawards limit. Foreshore slopes considering the entire active profile vary between $0.010-0.14(1: 100-1: 70)$ (Figure 8d). Moreover, the alongshore pattern shows a good correlation with the elevation of the $B_{m a}$. Fitting a linear relationship, a correlation coefficient of $r=0.82$ is found between the linear fit and the observed data (Figure 9). This observation supports our hypothesis that processes at the waterline are influenced by profile gradients along the entire active profile.

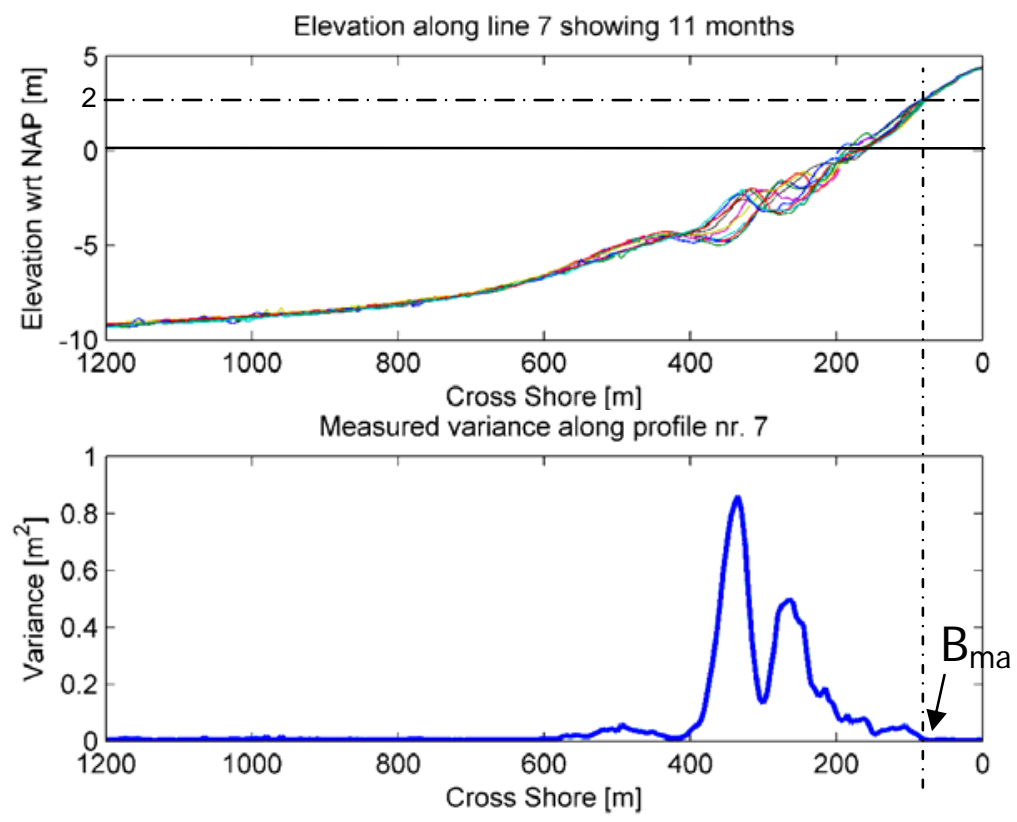

Figure 7 Top panel shows all measurement of profile $\mathrm{nr}$ 7. Bottom panel shows the temporal variance along the profile. 
A)

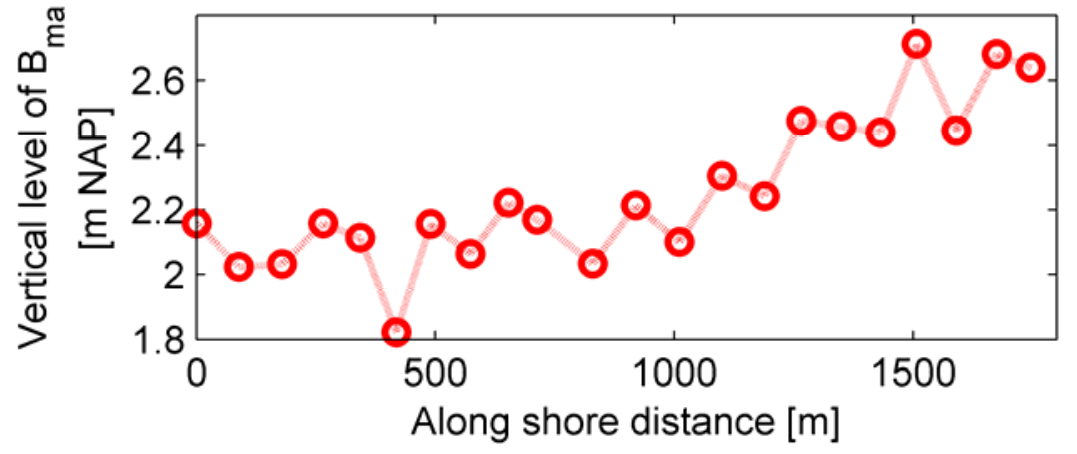

B)

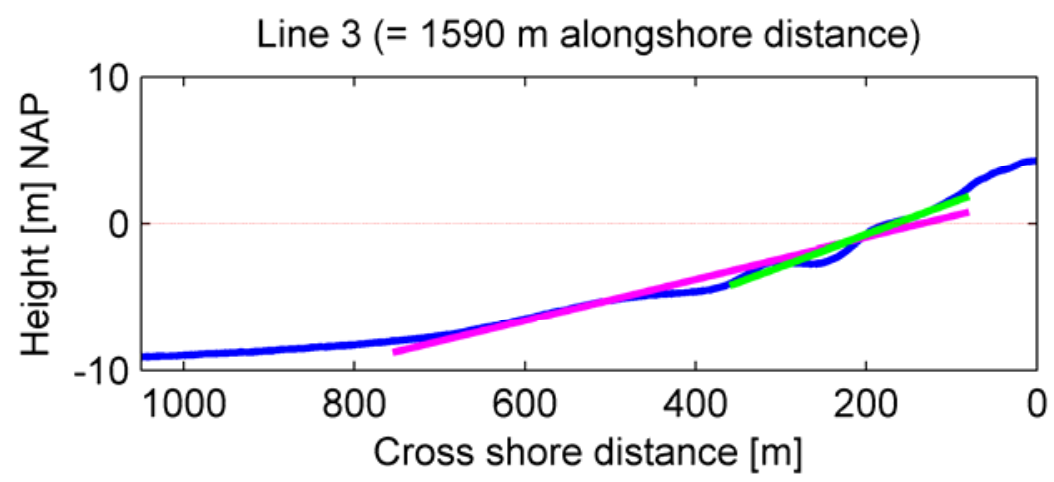

C)

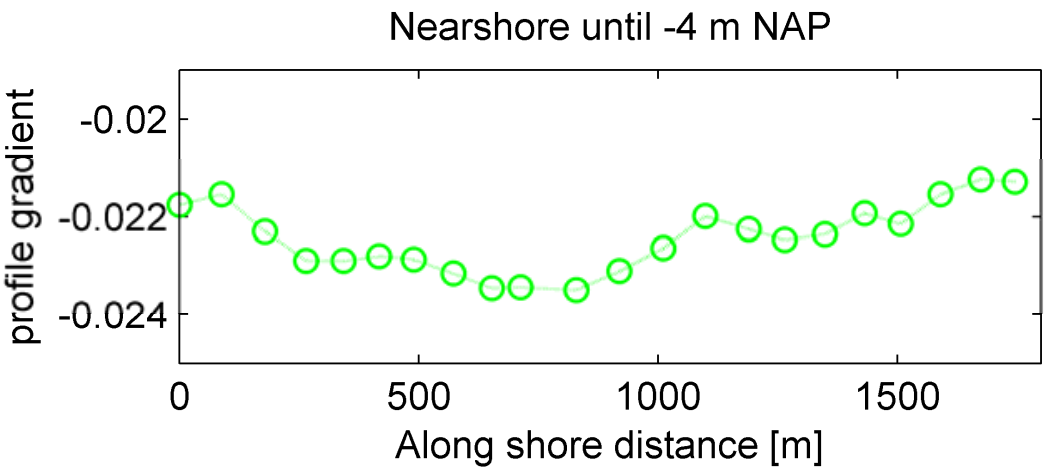

D)

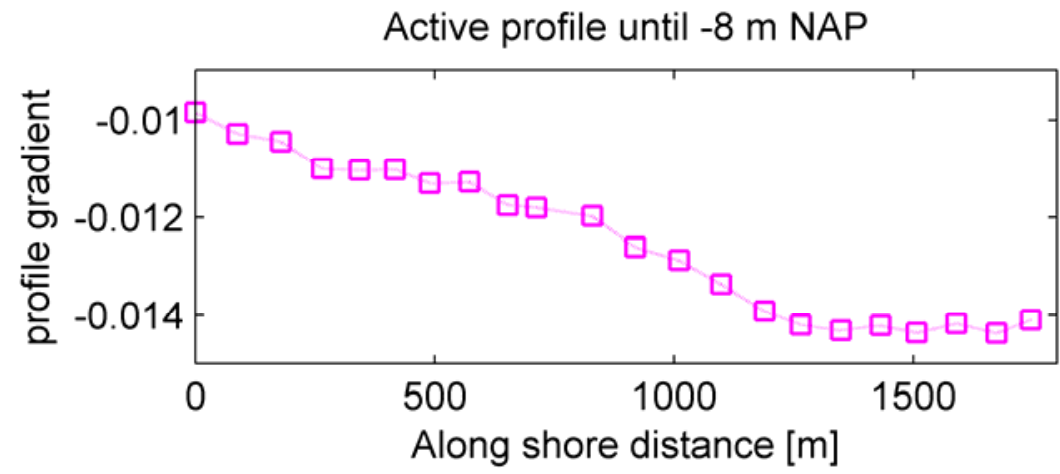

Figure 8. A) shows alongshore distribution of $B_{\text {ma. }}$ B) gives an example of the foreshore slopes using profile nr. 3. The best linear fit of the "very nearshore slope" is depicted in green and the entire active profile slope in purple. C) shows the alongshore variation in nearshore profile gradient. D) shows the alongshore variation of the active profile gradient 

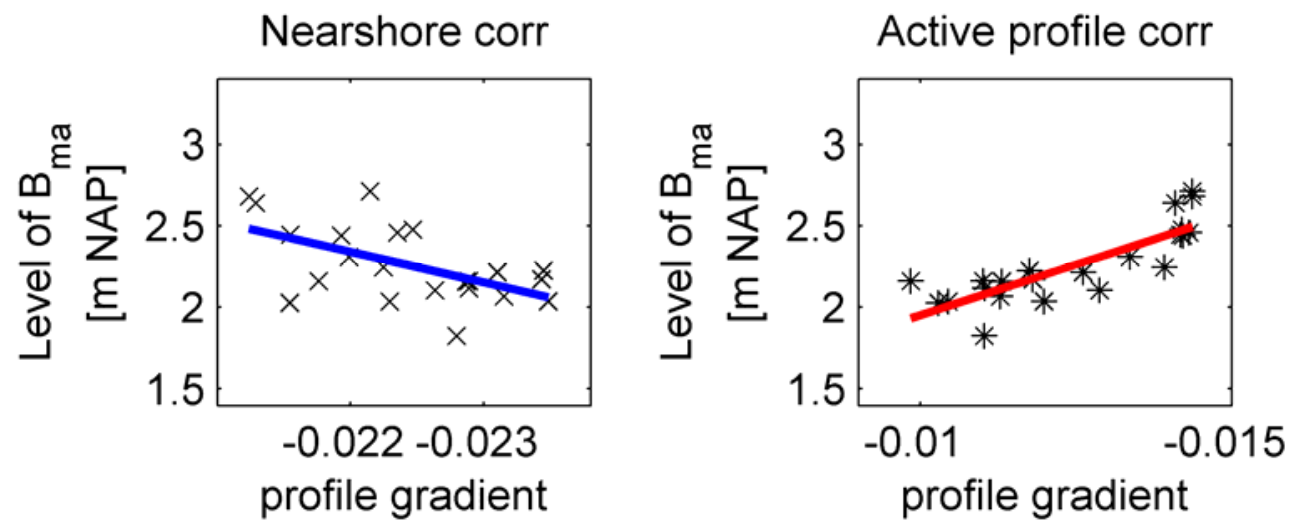

Figure 9. Left panel shows best linear fit correlation between the profile gradient of the nearshore zone and the elevation of the $B_{m a}(r=0.52)$. Right panel shows best linear fit correlation between the profile gradient of the active profile and the elevation of the $B_{m a}(r=$ 0.82).

\section{DISCUSSION}

The short term data used for this analysis contains only mild wave conditions (i.e. no storms occurred during the measurement period reported herein). This section discusses possible causes, effects and implications of a varying $B_{m a}$ for marine and aeolian processes as well as sediment parameters.

\section{Marine processes}

Hydrodynamic conditions and processes at the waterline are governed by tides, waves, wind and the morphology of the system. Assuming hydrodynamic conditions are constant alongshore, we have observed that the morphology of the system (active profile slope) influences the location of the border between the marine and aeolian zone.

It is well known that swash and wave transformation processes are influenced by foreshore slopes. Dimensionless normalized bed slope parameters are often used to quantify the transformation process for both short high frequency waves and low frequency waves associated with group signals (Battjes et al., 2004, Ruessink et al., 1998, Ruggiero et al., 2004). Offshore waves transform and eventually lead to swash excitation at the waterline $\left(B_{m a}\right)$ and for any given time the swash excitation is generally dominated by low frequency signals. Ruessink et al., (1998) found the amount of infra gravity wave influence and the amplitude of the runup to be dependent on the slope. These wave transformation processes are currently expected to be dependent on the foreshore slope of the shoaling zone rather than the active profile slope (Battjes et al., 2004). Based on the above analysis we suggest that wave transformations within the 'nearshore' shoaling zone may only play a minor role, while active profile morphodynamics may play a major role in governing processes at the waterline.

At this stage it is yet unclear what hydrodynamic process drives the alongshore variation of the $B_{m a}$. The assumption that the hydrodynamic conditions are constant needs to be validated. The Noorderdam of the entrance channel to the port of Rotterdam is located $2 \mathrm{~km}$ south of the measurement area. This dam has a seaward extent of $3.5 \mathrm{~km}$ and may influence hydrodynamic processes at the measurement area.

\section{Aeolian processes}

Aeolian processes are assumed to induce less variance along the profile than hydrodynamic processes. Therefore the location of the $B_{m a}$ is not expected to depend largely on aeolian processes. However aeolian processes themselves are very much influenced by beach width (Davidson-Arnott et. al. 2005). A larger beach width results in a larger supply area for aeolian transport to develop and therefore in a larger transport. An alongshore varying $B_{m a}$ corresponds to varying beach width. The measured $0.8 \mathrm{~m}$ difference in vertical level translates to a difference in horizontal distance $40 \mathrm{~m}$ if a typical slope of a 1:50 beach is considered. This horizontal distance of $40 \mathrm{~m}$ is significant as beach widths typically range between $90-200 \mathrm{~m}$ along the Dutch coastline. Ongoing research is expected to identify the dependence of aeolian processes on the observed beach width variations. 


\section{Exchange processes}

Based on this analysis limited insight in cross shore sediment exchange processes on the event scale has been gained. Future planned work includes analyzing the profile time series while taking chronology into account, and more importantly measuring and analyzing high energy events and subsequent beach recovery.

\section{Possible influence of grain size parameters}

No data are currently available to assess possible alongshore variations in sediment parameters. However, given the artificial nature of the site no significant differences in grain size parameters are to be expected. Generally the sand is collected from the same offshore mining pit. For this specific site it has been chosen to use particularly fine sediment. This fine sediment is easily mobilized by aeolian processes and will therefore speed up the morphological changes in the aeolian zone. Some redistribution in the cross shore direction is expected and has been measured in the aeolian zone.

\section{Varying timescales}

Morphologic behavior is very much divided in terms of variance. The proposed zonation based on measured variance suggests opportunities to define separate timescales which can vary along the coastal domain and/or with the process under consideration. Typically morphological changes due to aeolian processes are slower (less morphological change per unit of time) than due to hydrodynamic processes. Therefore, timescales representative for the governing processes differ. Moreover different timescales may also be defined based on the conditions considered. For example, erosive conditions during storm situations typically last for several hours to a few days whereas the following recovery period can last several months. Future analysis of the event scale data might provide more insight regarding this difference in response scales between zones and how they influence and are influenced by exchange processes.

\section{CONCLUSIONS \& FUTURE WORK}

A post nourishment field data set of monthly profile measurements covering one year obtained at Vlugtenburg beach, Holland has been acquired and analyzed. Based on this analysis we can hypothesize that: The elevation of the border dividing the aeolian and marine zone is dependent on slope of the entire active profile. This implies that conditions at the border between marine and aeolian zone are influenced by the entire active profile slope. The present data does not facilitate the process responsible for the measured variations and dominant inter-zone sediment exchange processes are yet to be determined.

Future work to expand the analysis aims to:

- Identify governing (hydrodynamic) process for conditions near the waterline.

- Determine specific implications for aeolian transport and dunefoot development.

- Specify mechanism of exchange processes between the marine and Aeolian zone.

- Determine possible site specific process parameters such as grain size parameters, shadowing and reflection effects by the dam.

- Explore possibilities for forcing-response quantification via numerical modeling. 


\section{REFERENCES}

Battjes, J. A., 1974. Surf similarity. In: Coastal Engineering. Am. Soc. Civ. Eng., Reston, Va., pp. 466-480.

Battjes, J. A., Bakkenes, H. J., Janssen, T. T., van Dongeren, A. R., Feb. 2004. Shoaling of subharmonic gravity waves. J. Geophys. Res. 109 (C2), C02009-.

Davidson-Arnott, R. G. D., MacQuarrie, K., Aagaard, T., 2005. The effect of wind gusts, moisture content and fetch length on sand transport on a beach. Geomorphology 68 (1-2), 115-129.

Hanson, H., Larson, M., Kraus, N. C., 2010. Calculation of beach change under interacting cross-shore and longshore processes. Coastal Engineering 57 (6), 610 - 619.

Ruessink, B. G., Kleinhans, M. G., van den Beukel, P. G. L., 1998. Observations of swash under highly dissipative conditions. J. Geophys. Res. 103 (C2), 3111- 3118.

Ruggiero, P., Holman, R. A., Beach, R. A., Jun. 2004. Wave run-up on a high- energy dissipative beach. J. Geophys. Res. 109 (C6), C06025-.

van Koningsveld, M., Lescinski, J., 2007. Decadal scale performance of coastal maintenance in the Netherlands. Shore and Beach Vol. 75 No. 1 (Winter 2007), 20-36.

van Son, S., Lindenbergh, R., de Schipper, M., de Vries, S., Duijnmayer, K., 2009. Using a personal watercraft for monitoring bathymetric changes at storm scale. International Hydrographic Conference. Cape Town, South Africa.

Wijnberg, K. M., Terwindt, J. H. J., 1995. Extracting decadal morphological behaviour from highresolution, long-term bathymetric surveys along the holland coast using eigenfunction analysis. Marine Geology 126 (1-4), 301 - 330, 1 